\title{
Foresight in designing sun-beach destinations
}

\author{
José M. Fernández-Güell*, Marta Collado \\ Universidad Politécnica de Madrid, School of Architecture, Department of Urban and Regional Planning, Avenida Juan de Herrera 4, 28040 Madrid, Spain
}

\section{H I G H L I G H T S}

- Foresight brings together key agents of change in order to develop future visions.

- Mass demand will experience a growing environmental consciousness.

- Tourism value chain will no longer be driven by demand, but by motivational centers.

- Airports will become more efficient, engaging and environmentally responsible.

- This method is user-friendly for decision makers and manageable for technicians.

\section{A R T I C L E I N F O}

\section{Article history:}

Received 29 October 2012

Accepted 14 September 2013

\section{Keywords:}

Futures studies

Foresight

Vision design

Strategic planning

Destination design

\begin{abstract}
A B S T R A C T
Foresight tools have been less used than forecasting methods by tourism planners because they seem to provide little added value to the planning process. To overcome this biased perception, this paper shows the potential of foresight for dealing with tourism development issues burdened by complexity and uncertainty, as well as its capability to bring down analysis from global challenges to local and spatial implications. A model framework is presented to incorporate foresight studies into the process of planning and designing tourist destinations. The model facilitates a gradual transition from a narrative vision to the spatial design of a future destination. Stakeholders play a very important role in the proposed model, being involved throughout the process in identifying future trends, formulating visions and helping to design urban patterns. In order to facilitate stakeholders' involvement, various analytical and design tools are used to envision the future development of tourist destinations.
\end{abstract}

(c) 2013 Elsevier Ltd. All rights reserved.

\section{Introduction}

Although future prediction has been a long-standing quest, future studies have a mere half-century of existence as a recognized field of scientific knowledge. Since ancient times, people have been uneasy when faced with uncertainty, and have tried to anticipate their future by different means, from priestly prophesy to rational thinking by scientists. It was not until the 1950's and 60's that a formal body of knowledge known as Future Studies began to be assembled with a view to providing researchers with a new set of tools.

Different methods have been used to classify future studies (Armstrong, 2001; Jantsch, 1967; UNIDO, 2005), but most practitioners tend to make a broad categorization between quantitative

\footnotetext{
* Corresponding author. Departamento de Urbanística y Ordenación del Territorio, Escuela de Arquitectura, Avenida Juan de Herrera 4, 28040 Madrid, Spain Tel.: +3491 3365251; fax: +34913366534.

E-mail addresses: josemiguel.fernandez@upm.es (J.M. Fernández-Güell), mclcollado@hotmail.es (M. Collado).
}

and qualitative methods. In this respect, a basic distinction is made between forecasting and foresight.

- Forecasting visualizes the future as a unique, linear, evolutionary process based upon past experiences. The predicted future is clearly deterministic. Forecasts are mainly nurtured by quantitative tools.

- Foresight contemplates the future shaped by complex, uncertain and multiple visions. The future is open and not predetermined. Foresight mostly employs qualitative tools.

The use of foresight studies is now spreading, and they are becoming a decisive part of many planning exercises, especially in technology, business, environment and energy related areas (European Commission, 2009). This trend is due to fast, unpredictable changes in society, markets, technology and science. This dynamic and sometimes turbulent environment puts enormous pressure on rational planning systems, many of which have been designed to simulate highly stable and predictable functional systems, while foresight methods have fewer technical constraints and 
are more adaptable to environmental changes (Abott, 2005; Fernández Güell \& Redondo, 2012).

Obviously, tourism planning has not been oblivious to the need to foresee the future and limit uncertainty. Since its inception in the middle of the 20th century, tourism planning has made many projections and anticipated trends in order to improve the design of destinations for the benefit of visitors, investors and local residents. Nevertheless, when it comes to planning and designing destinations, tourism planners have preferred to use quantitative tools to project visitor numbers, revenue and economic impact rather than apply qualitative tools (Goodwin, 2008; Song \& Li, 2008). Even tourism researchers seldom combine quantitative and qualitative tools in an integrated framework (Davies, 2003).

In our view, several arguments support the application of foresight to tourism planning. First of all, the complex, heterogeneous nature of tourism components (Darbellay \& Stock, 2012) makes forecasting rather difficult. Second, global trends that play as drivers of tourism change force planners to anticipate changes in visitors' behavior, technological innovations and competitors' initiatives (Dwyer, Edwards, Mistilis, Roman, \& Scott, 2009). Third, the increasingly unstable nature of the tourism context justifies the use of foresight tools to foresee the future (Butler, 2009). Fourth, a natural symbiosis between foresight and spatial planning helps to make a tourism plan more holistic and imaginative (Cole, 2001). All of the above seem to be plausible reasons for applying foresight to traditional planning processes.

Despite its apparent benefits, foresight is either simply ignored or perceived as an irrelevant set of tools that provide little added value to spatial planning processes (Myers \& Kitsuse, 2000; Wachs, 2001). On the one hand, most foresight exercises by social scientists are usually based in general narratives that are intellectually stimulating but rarely of much help to tourism planners for their actual design decisions. On the other hand, when looking at the future, physical planners tend to focus on forecasting tools, disregarding most foresight methods as frivolous exercises that simply provide imprecise visions. Finally, most foresight exercises are too expensive as to be afforded by medium-size municipalities.

Therefore, assuming that there is a need for reinforcing foresight approaches into spatial planning processes, the challenge brought up in this paper is how to incorporate foresight tools specifically into the process of planning tourism destinations. To achieve this goal, a conceptual framework is presented hereby in which planners and tourism stakeholders alike can make friendly use of foresight tools at a reasonable cost.

\section{Foresight contributions to the planning process}

Foresight is a relatively new field of study. It initially arose to make provisions for the future in science and technology, but nowadays it is increasingly used in territorial issues such as climate change, urban development and transport systems. When applied to territorial issues, foresight may be defined as a systematic, participatory, future intelligence gathering and vision-building process aimed at making present-day decisions and mobilizing joint action in the territorial realm (Fernández Güell, 2006; Gavigan \& Scapolo, 2001). In other words, foresight brings together key agents of change and sources of knowledge in order to develop strategic visions and anticipatory intelligence in a given territory.

Foresight can thus contribute five essential aspects to territorial planning processes (FOREN, 2001):

1) Anticipation. Foresight is a structured way to anticipate and project long-term social, economic and technological developments and needs.
2) Vision. Foresight provides a guiding strategic vision with a shared sense of social commitment about a certain issue.

3) Action. Foresight develops and implements strategic visions through detailed action plans, which enable contemporary actions to face the future successfully.

4) Participation. Foresight intensively incorporates interactive and participatory methods that foster debate and analysis with a wide variety of stakeholders.

5) Networking. Foresight forges new social networks for the exchange of ideas, experiences and specific knowledge.

In contrast to traditional planning processes, which tend to have a limited sectoral scope, foresight gradually builds up an integrated vision of the possible future through participatory methods. Foresight is thus complementary to the established planning processes, feeding into them new elements and values, empowering local stakeholders and providing legitimacy to territorial strategies.

There is a synergy between foresight and strategic planning (Fernández Güell, 2011). The need to think about the future and formulate long-term visions makes strategic planning a perfect application for foresight tools, while the need for stakeholder collaboration in strategic plans is well matched to the participation and networking attributes of foresight processes.

Foresight practitioners have a wide variety of well-documented methods and tools at their disposal (Armstrong, 2001; EFP, 2012; UNIDO, 2005). Standard, well-tested foresight methods such as Delphi, scenario design, trend analysis and visioning, which are now widely and successfully used in almost every field of knowledge, and newly developed techniques such as Four Quadrants (Slaughter, 1999) and Causal Layered Analysis (Inayatullah, 2004) are gradually making their way into the field.

The rapid acceptance of foresight methods in a wide-array of knowledge fields has contributed to a thorough assessment of their benefits and disadvantages (European Commission-JCR-IPTS, 2005; FOREN, 2001; Georghiou, Cassingena, Keenan, Miles, \& Popper, 2008).

Foresight can provide many tangible benefits for tourism planning. Firstly, it systematizes the debate about future prospects for tourism development amongst a wide variety of stakeholders by building up plausible, coherent future visions. Secondly, it helps to formulate viable, innovative tourism strategies that can reconcile the viewpoints of a wide range of stakeholders. Thirdly, it forms expert networks to exchange and disseminate knowledge deriving from the foresight exercises amongst stakeholders and political decision-makers.

Foresight may, however, also have disadvantages for tourism planning. In the first place, foresight cannot tackle or resolve all the social, economic, environmental and political problems of a given tourism destination. Secondly, foresight cannot impose consensus where there are deep disagreements between stakeholders. Thirdly, foresight is not a quick remedy for urgent problems because it requires long analyses and expert networks that do not produce immediate results. Finally, foresight requires policies that may be difficult to implement in emerging public institutions with little real power.

\section{The elusive presence of foresight in tourism planning}

A recent search was undertaken in internet to detect and assess tourism foresight exercises carried out by relevant organizations involved in tourism research and planning. This search was completed with a literature review of major foresight and tourism scientific journals. Findings were grouped in two geographical levels: international and national. 


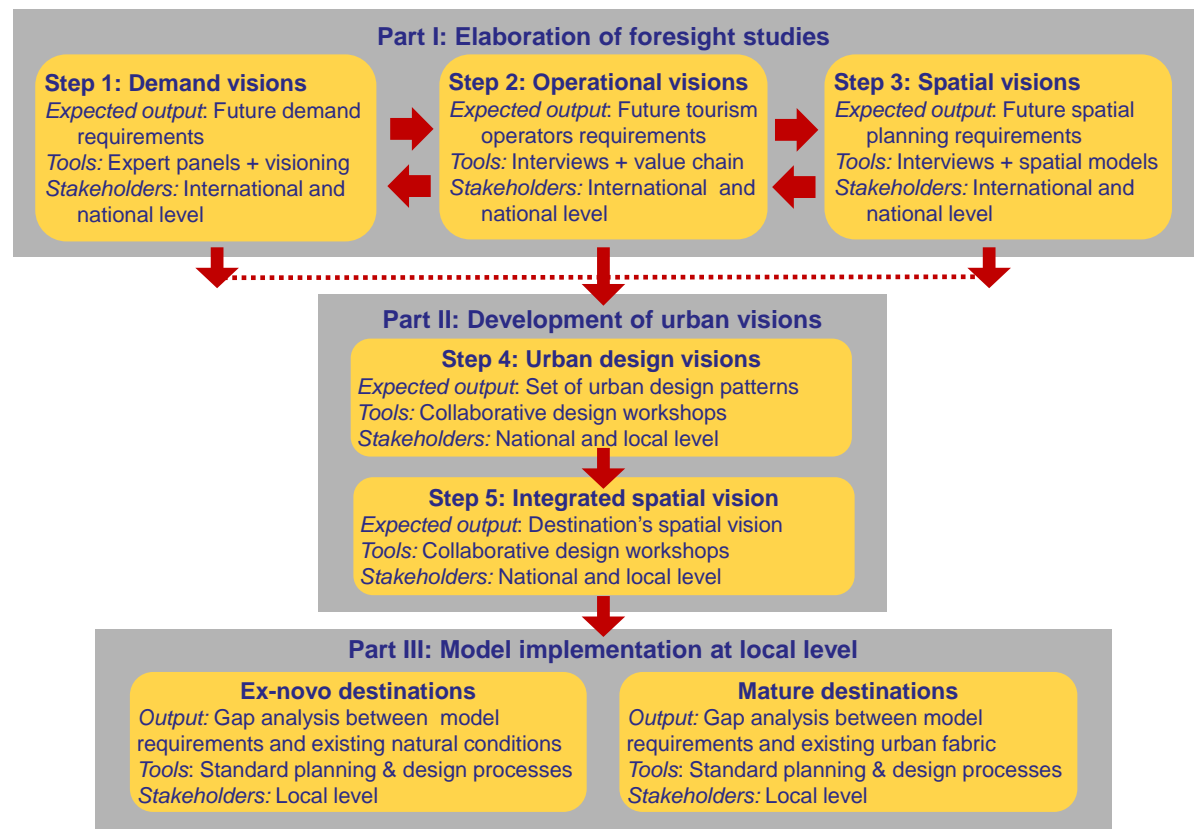

Fig. 1. Linking foresight and tourist destination planning. Source: Author.

At the international level, it has been detected that institutions such as the World Tourism Organization (WTO) and the Organization for Economic Co-operation and Development (OECD) are more focused on forecasts than qualitative visions or scenarios. Nevertheless, both institutions have made partial incursions into the qualitative field by identifying megatrends for the purpose of producing quantitative forecasts, assessing developmental and marketing factors, and providing policy guidance (OECD, 2010; WTO, 2001, 2006, 2011).

Besides the work of international institutions, little research and consulting work has been done worldwide on tourism foresight. A recent research project mapped 1.000 foresight exercises worldwide, which were registered during the 2005-2008 period (European Commission, 2009). This study established that the most popular socio-economic sectors targeted in foresight work were engineering and technology, social sciences, manufacturing and natural sciences, while tourism related sectors, such as hotels and restaurants, were less inclined to use foresight methods.

Within European Union related organizations, evidences are also scarce. Searches undertaken at the Institute for Prospective Technological Studies and the European Foresight Platform have revealed only two foresight cases related to the tourism sector (Amelung \& Moreno, 2009; Mittringer, 2005). Finally, no explicit references to foresight exercises have been detected in the technical reports delivered by the High Level Group on Tourism (1998) and the Tourism Sustainability Group (2007), two stakeholders' platforms established by the European Commission to advice on tourism policy.

At the national level, tourism institutions are beginning to make tentative explorations into the foresight field, but evidences are still uneven. On the one hand, some Mediterranean countries, who are truly powerhouses in sun-and-beach tourism, have little experience in foresight-related exercises. Using Spain as a representative case, few incursions have been made into the foresight field. In 2007, the Consejo Español de Turismo (Spanish Tourism Council) made a general assessment of the major trends that might affect the tourism sector for the 2020 horizon. A far more explicit foresight exercise was undertaken by the Observatorio de Prospectiva
Tecnológica Industrial (OPTI) in 2005, when future scenarios were designed to anticipate trends in global tourism demand on the 2015 horizon. However, foresight tools have hardly been used when planning at the municipal level.

On the other hand, in Northern European countries foresight seems to have been more widely accepted as part of regional and local planning processes. In Scotland, four scenarios were created to foresee Scottish tourism in 2015 and subsequently maximize the potential of the tourism industry (Yeoman \& Lederer, 2005). In Nederland, the Island of Texel developed a Tourism Master Plan, in which a set of future scenarios were used as an integral part of the strategic spatial planning process with the purpose of making a contribution to the public debate and decision making (Duim \& Calders, 2004).

A review of major foresight and tourism scientific journals did not unveil a great number of tourism foresight exercises. Since the 1980s, leisure and tourism journals have published several articles related to the Delphi Method and Scenario Design, two of the most popular foresight tools (Kaynak \& Macaulay, 1984; Richins, 1997; Van Doorn, 1986); however, they have not paid much attention to foresight as an integrated approach that may help planners in foreseeing the future with the involvement of tourism stakeholders. On the other hand, scientific journals specializing in futures studies (Futures, Foresight, Technological Forecasting and Social Change, and the Futurist) have published some articles referred to foresight in tourism (Amorim, Melo, Alvarenga, \& Soeiro, 2011; Chambers, 2009; Cole \& Razak, 2009), but without stressing the link of foresight tools with the planning process.

Just recently, the Journal of Sustainable Tourism has dedicated a special issue to discuss the relationships between mobility and sustainable tourism (Lund-Durlacher \& Dimanche, 2013). The implications of people, capital, labor and resources mobility on destination planning and governance may provide interesting clues for foresight exercises.

In brief, our search efforts have revealed the relative scarcity of foresight exercises in the tourism domain. As a result, there seems to be an opportunity to further promote the use of foresight tools among tourism and spatial planners. 


\section{Proposed model framework}

There are plenty of references in the tourism literature regarding the need for improving planning models (Getz, 1986; Hall, 2008; Inskeep, 1988) as well as for integrating tourism and spatial planning when designing destinations (Chettiparamb \& Thomas, 2012; Dredge, 1999; Dredge \& Moore, 1992; Gunn \& Var, 2002); however, there are no relevant contributions about the leading role that foresight may play in the planning process. As stated in the introduction, a mixture of ignorance and lack of credibility of foresight tools may explain this situation.

In order to make foresight techniques attractive to tourism planners, the quality and detail of the qualitative tools (such as visions or scenarios) should be improved to facilitate their use as inputs for quantitative and design tools. With this purpose in mind, the following model tests the applicability of foresight tools for planning and designing tourist destinations, and illustrates the way a future vision can lead to practical strategies that guide the development of a tourist destination.

This model framework consists of three parts and five sequential steps (see Fig. 1) which rely on on-going, systematic participation by tourism experts and stakeholders.

Part I: Elaboration of foresight studies. Firstly, future visions are formulated and operational and spatial planning implications are inferred from the visions. Part I is made up of three steps, which rely heavily on the involvement of tourism experts and foresight practitioners.

Step 1: Demand visions. Standard foresight tools such as visioning or scenario design are used to create future visions of global tourist demand. Qualitative foresight tools are strongly recommended because they facilitate stakeholder participation. Step 2: Operational visions. Once future demand visions are formulated, the operation of the tourism value chain and the role of tourism operators in a highly competitive market can be shown. This analysis uses operational flows diagrams to visualize how travel operators act.

Step 3: Spatial visions. Future visions and value chain operations provide plenty of clues for establishing a set of spatial guidelines for the development of a mass tourism destination in a competitive market. This step mostly relies on analytical and graphic tools.

Part II: Development of urban visions. Once future functional and spatial requirements are established, urban patterns are designed to show how these requirements will be spatially implemented in generic destinations. Part II is made up of two steps, which require the involvement of industry experts as well as physical planners and designers.

Step 4: Urban design visions. Urban design patterns schematically display spatial arrangements for major tourism infrastructure and facilities.

Step 5: Integrated spatial vision. Urban design patterns are brought together for an integrated spatial vision of a tourism destination.

Part III: Model implementation at local level. Though the third part is out of this paper's scope, it is important for the relevance of the whole approach. Previous steps provide inputs for developing a conceptual model that could be applied to any destination. Reaching this point, planners could apply the model either to exnovo or mature destinations. In both cases, a gap analysis follows by comparing model requirements and existing conditions, but obviously resulting processes differ substantially. From this point
Table 1

Number and profile of stakeholders involved in foresight studies.

\begin{tabular}{|c|c|c|c|}
\hline \multirow[t]{2}{*}{ Stakeholders profile } & \multicolumn{3}{|c|}{ Foresight studies } \\
\hline & 2005 & 2007 & 2009 \\
\hline $\begin{array}{l}\text { Tour Operators (TUI, Thomas Cook, El Corte Inglés, } \\
\text { Kuoni, TSS-Touristik) }\end{array}$ & 2 & 1 & 4 \\
\hline $\begin{array}{l}\text { Travel Agencies (Amadeus, eDreams, Lastminute, } \\
\text { Atrápalo, AEDAV, others) }\end{array}$ & 3 & 1 & 4 \\
\hline $\begin{array}{l}\text { Transport Operators (Iberia, British Airways, } \\
\text { Renfe, AENA) }\end{array}$ & 2 & 3 & 1 \\
\hline $\begin{array}{l}\text { Hotels and Apartments (Paradores, NH, Sol Meliá, } \\
\text { Marbella Club, Fuerte, others) }\end{array}$ & 3 & 5 & 3 \\
\hline $\begin{array}{l}\text { Sport \& Leisure Services (Sancti Petri Golf, Promotur, } \\
\text { Golf Montenmedio, others) }\end{array}$ & & 5 & \\
\hline $\begin{array}{l}\text { Natural Parks close to sun and beach destinations } \\
\text { (Grazalema, Cazorla, others) }\end{array}$ & & 5 & \\
\hline $\begin{array}{l}\text { Cultural Attractions close to sun and beach } \\
\text { destinations (Granada, Jerez, others) }\end{array}$ & & 6 & \\
\hline $\begin{array}{l}\text { Tourism Business Associations and Trade } \\
\text { Unions (CEA, CEHAT, AEHCOS, others) }\end{array}$ & 1 & 6 & \\
\hline $\begin{array}{l}\text { Consulting and Technology Firms (Google, } \\
\text { Microsoft, Experian, AUIA, others) }\end{array}$ & 6 & 4 & 3 \\
\hline $\begin{array}{l}\text { Public Administrations (Turespaña, various } \\
\text { provincial and municipal tourism offices) }\end{array}$ & 2 & 12 & 2 \\
\hline $\begin{array}{l}\text { Universities and Think Tanks (WTO, Exceltur, } \\
\text { SEGITTUR, Deusto University, others) }\end{array}$ & 6 & 5 & 3 \\
\hline Subtotals of stakeholders & 25 & 53 & 20 \\
\hline
\end{tabular}

Source: Author.

forward, standard planning and urban design procedures should be employed.

Though the approach is depicted as stepwise and linear, it definitely is not. Iterations cycles are possible, while there is also a mutual influence between different steps.

Stakeholders play a very important role in the proposed model. As advocated by researchers in the field of collaboration theory (Dredge, 2006; Jamal \& Getz, 1995; Quist, 2009; Sautter \& Leisen, 1999), stakeholder groups are to be identified and involved at an early stage in the process. Given the complexity of the proposed model, stakeholders' contributions will differ upon the stage of the process in which they participate. In Part I, stakeholders are expected to provide expertise about future trends from a wide range of viewpoints, deal with uncertainties, structure complex problems and legitimate the vision formulation process. In Part II, stakeholders help planners to transform future visions into spatial models and urban design patterns, assessing their feasibility. In Part III, stakeholders collaborate at implementing the model, which empowers local tourism operators and increases their accountability as they become co-responsible for decision making. Above all, stakeholders' involvement along the process should promote mutual learning between private and public tourism agents, stimulate community participation, endorse planning results and create ownership of the foresight and planning process.

The proposed model is a conceptual approach that, in principle, could be used in any kind of tourism destination, regardless of geography or specialization. Nevertheless, this model can be particularly relevant to mass sun-beach destinations because of their functional complexity, intense involvement of tourism operators and holding of large volumes of visitors.

Since most of the proposed steps have been used previously in tourism planning, this approach is not completely new, however it is novel in the sense that all the elements are used in an articulated and coherent way, using a foresight exercise as the starting point. In brief, three major contributions are made by the model: (1) it integrates foresight into the process of planning tourist destinations; (2) it incorporates various analytical tools to facilitate stakeholders' involvement in visioning the future; and (3) it makes foresight 
more affordable to small and medium-size municipalities by providing a generic model that could be applied to multiple destinations.

\section{Methodology}

The proposed method was developed over an eight-year period. Due to the scarcity of research resources and the complexity of the topic, progress was made in a slow, piecemeal approach in different consulting projects and academic activities. The chronological sequence was roughly as follows.

In the year 2005, a foresight exercise was undertaken by OPTI to design a series of future scenarios for the global tourism demand with a 2015 time horizon and to determine the scenarios impacts on the Spanish tourism sector. This exercise involved a two stage participatory process with expert panels: a half-day workshop for identifying and assessing change trends that may affect tourism demand behavior and another half-day workshop for building scenarios. A total of 25 experts participated in the panels (see Table 1). They were selected according to their recognized expertise and their ability to envision the future. Workshops were complemented by 17 personal interviews.

Along 2007 and 2008, a follow-up study was carried out in Andalucía, a Southern region of Spain, to determine implications of the 2015 scenarios. At that time, 53 personal semi-structured interviews were held with local stakeholders involved in the development of tourism products and services in the coastal areas of Andalucía (see Table 1). Interviewees were asked to comment on trends and scenarios, and to explore business and territorial implications of future scenarios. As a result of this study, the 2015 scenarios were revised and the time horizon was extended to 2025.

In 2009, a selected group of 20 experts were interviewed to discuss the operational and spatial requirements posed by the updated future vision of tourism demand (see Table 1). Interviews, based on semi-structured questionnaires, required two hours each and were complemented with additional information offered by the experts.

During 2011, evidence of foresight tools in tourism planning was gathered from secondary sources. An internet search was undertaken to spot academic and technical publications that included foresight tools in tourism planning processes. At this time, it was made clear the need for developing a conceptual framework to link foresight and tourism planning.

Finally, in 2012 urban patterns for sun and beach destinations were developed in lab work with doctoral students. Spatial arrangements were displayed on the basis of information gathered in the previous studies and in various secondary sources. Lab work was revised by three Spanish consulting firms with relevant experience in planning sun and beach destinations. These experts checked out the work process of translating future visions into spatial designs and they assessed the involvement of stakeholders in the design process. Therefore, at this stage most work was done by researchers and supplemented with expert participation, which differs from broad stakeholder involvement.

Although the use of diverse, fragmented resources over a long period may seem to be a very inefficient and tortuous way of conducting research, this approach has allowed us to contrast ideas and tools parsimoniously in a little-explored field of knowledge.

\section{Implementing the model framework}

In the following sections, the five methodological steps are implemented in a fictitious exercise for a generic sun-and-beach destination on Spain's Mediterranean coast which receives more than 300,000 visitors every year. Although the case refers to a
Mediterranean context, it may well be applicable to other international destinations. This case should be treated as a simple demonstration of the kind of results that can be obtained with the proposed methodological approach. Therefore, debate should not be focused so much on the partial findings of each methodological step as on the feasibility of the whole approach.

\subsection{Step 1: demand visions}

Recent foresight exercises undertaken for the Spanish tourism sector (OPTI, 2005; OPTI \& Junta de Andalucía, 2008) revealed that on the year 2025 horizon, two major demand segments will clearly dominate the tourism market: "Massive and Predictable Tourism" and "Niche and Innovative Tourism". In the context of this study, "mass tourism" is understood to be made up of large segments of travelers, who will be well differentiated in terms of geographical origin and socio-demographic structure, but will show similar values and behaviors when consuming standardized tourism experiences. On the other hand, the term "niche tourism" encompasses a multitude of micro segments of great diversity and complexity, which will preferably consume highly specialized tourism products. Tough these two segments do not reflect the complexity and variety of future tourism demand, they provide an overall picture of the driving forces that will guide tourist behavior and consumption trends in the coming years.

Our research project focused on the future profile of sun-andbeach mass tourism and it was based on the contributions made by stakeholders in the above mentioned Spanish foresight studies. Most stakeholders' views were consistent with recent research and professional literature regarding tourism trends (Dywer et al., 2009; IPK, 2012; Yeoman, Rebecca, Mars, \& Wouters, 2012).

Workshop participants agreed that mass tourism will persist as the most voluminous segment in the tourism market. Continuing past trends, many families with children and large tourist groups will feed the ranks of sun-and-beach destinations. One of the most dynamic groups in this segment will be "Seniors", in the over-60 age group, who will travel more than before and will have more diverse and demanding traveling requirements.

Future mass tourism will be less sophisticated and capricious than niche tourism; however, it will require high quality, reliable services. It will demand thoroughly tested tourism products as well as massively consumed destinations.

The mass tourism segment will maintain its traditional motivations for traveling - relaxation, beach, recreation and escape from routine-, however cost will increasingly be one of the key motivating factors for traveling. Seasonal trips to beach destinations will still be a priority for this segment, but tourists will increasingly choose emerging sun-and-beach destinations to get better value for money. Mass tourism will become increasingly environmentally aware, although not as intense and explicit as Niche tourism. Many tour operators will conduct campaigns to make tourists aware of the environmental costs generated by their travel. Sustainability will also become a major tag in most destinations marketing strategies.

By 2025, the internet will be the dominant channel for finding and evaluating travel offers. Most mass travelers will have easy and ubiquitous access to internet and will use all kinds of electronic devices to gather and interpret tourism information. Intelligent search engines will greatly help consumers to choose from amongst an unlimited and highly competitive supply of tourism products.

When buying a sun-and-beach product, mass travelers will make their decision on the basis of value for money, safety conditions and the existence of events. Trips to well-known sun-and-beach destinations will be bought via the Internet, but exotic and emerging resorts will still require the support of specialized travel agents. 
An aging tourist population and a more evenly spread school calendar through the year will help to reduce the seasonality of sun-and-beach destinations. Mass travelers will spend shorter periods on their holiday trips, but they will probably travel more often. Mass tourism will require a wide variety of services and recreational activities at reasonable prices in coast destinations. Entertainment facilities will become more sophisticated and diverse, offering added value to the tourism experience.

Evaluation of the tourism experience will be done through different channels, preferably the internet, and it will be performed in real time. Mass travelers will be able to evaluate instantly a whole destination or a specific service by just browsing a blog or a web page. Their assessment of the tourism experience will be mostly determined by objective parameters such as accommodation quality, services efficiency or safety standards. Mass tourism opinions will be highly considered by tour operators and destination managers as valuable feedback for redesigning products and facilities.

The above vision can also be presented by displaying the consumption process (see Fig. 2) used by standard marketing (Engel, Blackwell, \& Miniard, 1990).

A similar vision to this, along with narratives of the socioeconomic context is usually the final product of many foresight exercises. While stimulating, these visions do not provide much insight about the analyzed topic. In order to improve these shortcomings, the method continues to define the operational and spatial implications.

\subsection{Step 2: operational visions}

The second methodological step defines the operational requirements of the organization and management of the tourism value chain. Though the concept of the value chain was popularized by Prof. Michael Porter in the 1980s (Porter, 1980), the idea of visualizing production processes by sequencing them into production chains has a longer tradition in Economics and an increasing presence in the tourism industry (Romero \& Tejada, 2011; Zhang, Song, \& Huang, 2009).

The essential idea in value chains is that each link adds value to the product. Using value chain analysis has major advantages (Romero \& Tejada, 2011): (1) it shows the impact of changes in technology, demand, competition or entrepreneurial strategies on the tourism industry; (2) it takes an interest in any type of interfirm linkages, regardless of their spatial location; (3) it reflects the role of large multinational corporations and SMEs in production process; (4) it takes into account managerial variables which do not always have a direct and easy quantitative expression.

Applied to the tourism sector, the value chain may be described as a set of sequential operations that are undertaken by tourism operators to deliver products and services that satisfy travelers' motivations and needs. Stakeholders' opinions documented in recent foresight studies (OPTI, 2005; OPTI \& Junta de Andalucía, 2009) provided an integrated view of the sun-and-beach value chain on the 2025 horizon (see Fig. 3).

Most stakeholders agreed that the tourism value chain will no longer be driven directly by demand, but by "motivational centers". These centers will be made up by diverse agents such as social networks, internet blogs or marketing agencies, who will generate multiple motivations for traveling. Motivations will be segmented and marketed to well-differentiated lifestyles. Motivational centers will heavily influence the design of tourism products and will master the principles and tools of behavioral marketing.

Once potential travelers are motivated, they will enter the tourism value chain. Conventional tour operators will still exist in 2025 , but their former market dominance will be very much eroded by the emergence of very powerful and dynamic on-line channels. Tourist packages will be sold on-line, enabling consumers to fabricate their own products.

On-line travel agencies will clearly dominate the sector, but offline agencies will still survive. The business of on-line agencies will be based on very low costs, small margins and large volumes, while at the same time they will need to invest heavily in technology to maintain their competitive position. On the other hand, off-line

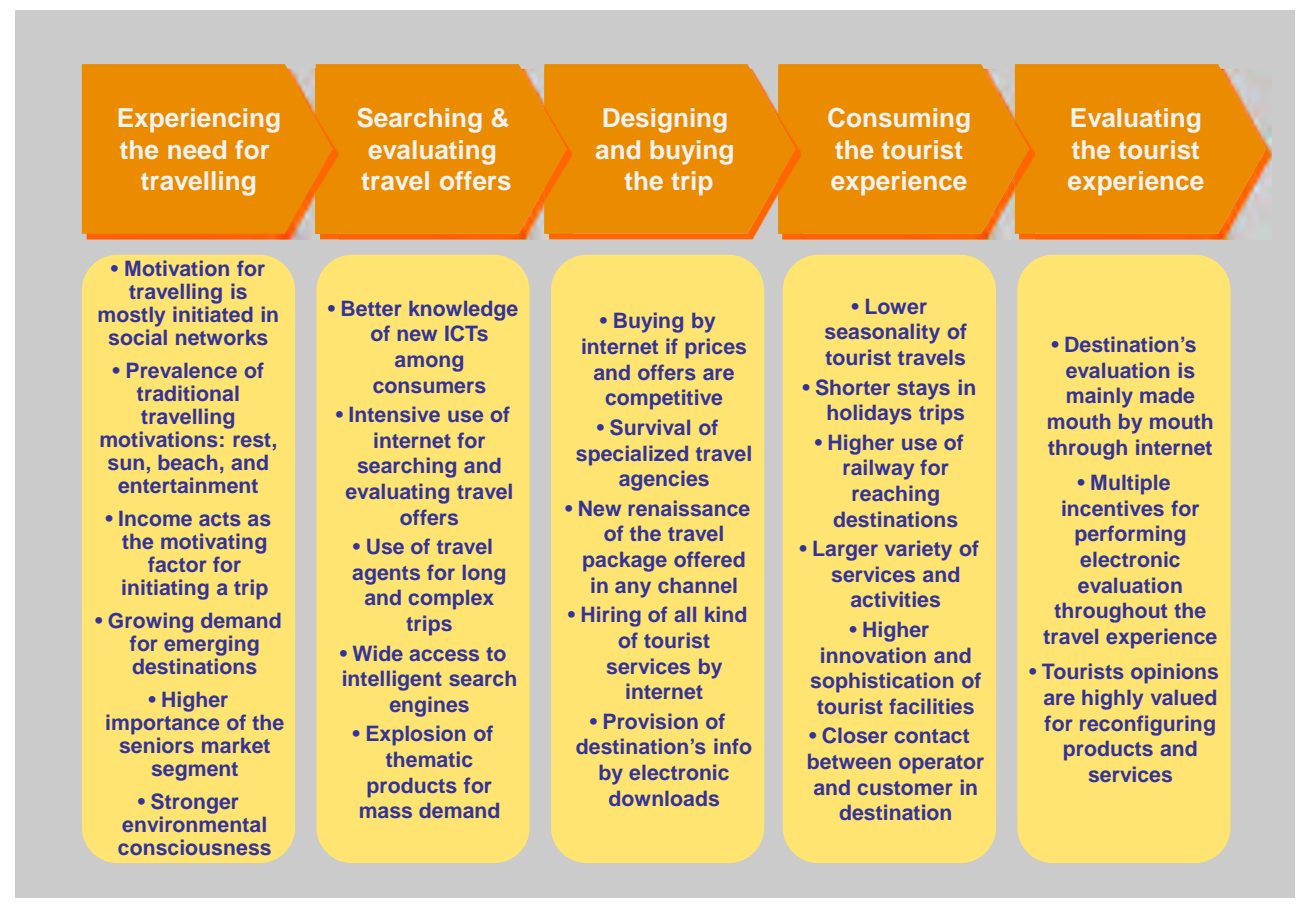

Fig. 2. Future consumption process in mass tourism (2025). Source: Author's elaboration on OPTI and Junta de Andalucía (2008). 


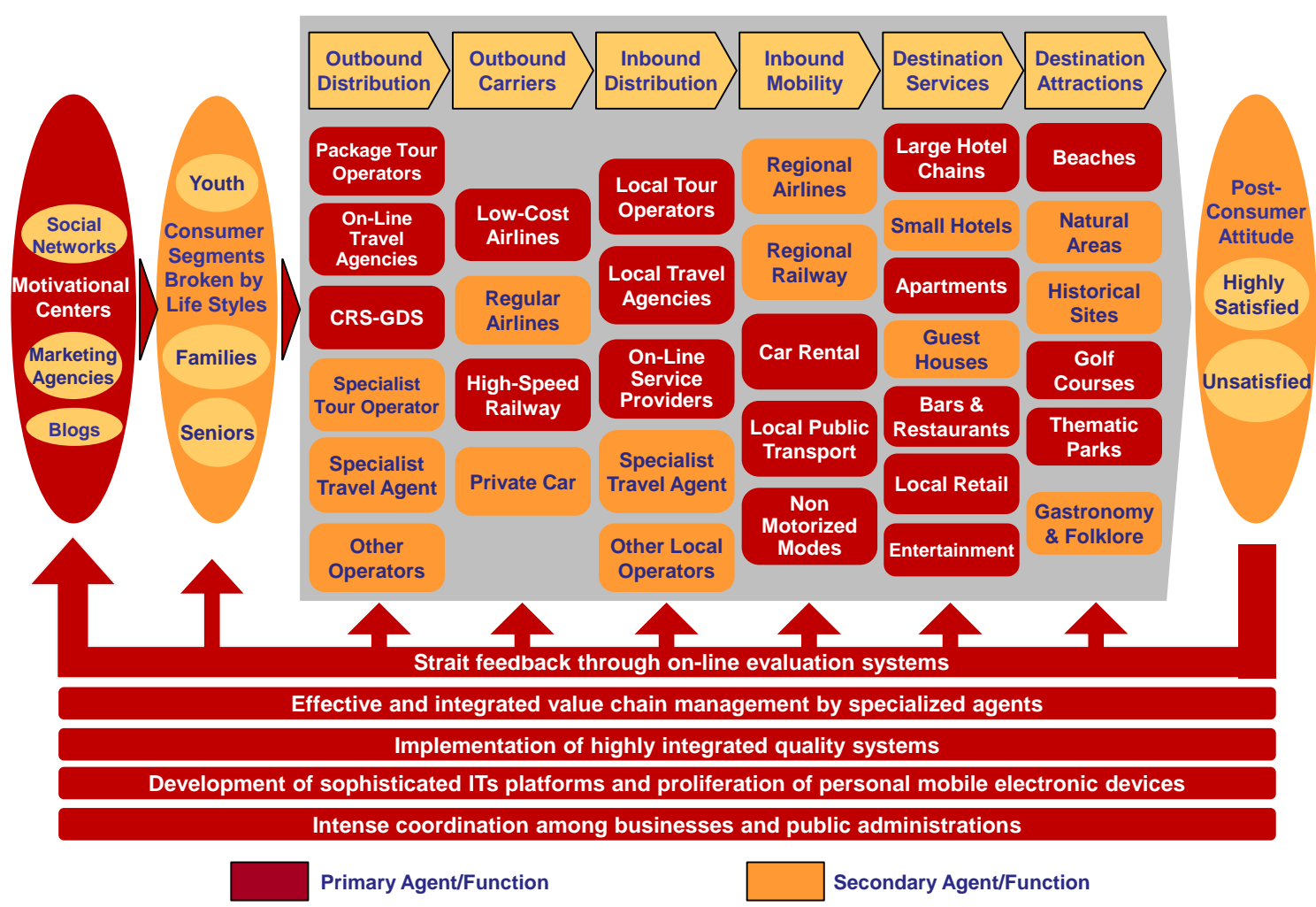

Fig. 3. Tourism value chain for sun-and-beach mass tourism (2025). Source: Author's elaboration on OPTI and Junta de Andalucía (2009).

agencies will have to focus on specific market niches and reach a high level of specialization to prosper in this scenario.

The recurrent energy crisis will trigger the transformation of transport systems. Moving large volumes of tourists will require efficient connections between mega-hubs, medium-size airports and railways networks. Low-cost airlines will provide direct medium-range flights between large markets and major tourism destinations, while regular airlines will maintain their market control over long-haul international flights. High-speed trains will revolutionize traveler mobility over medium-range distances (under $700-800 \mathrm{~km}$ ), and will be increasingly used to reach beach destinations.

Hotels will provide the highest added value of tourist services, and large hotel chains will therefore lead the tourism sector by identifying market segments, designing innovative products, selling products through direct channels and providing specialized services. Hotels will be a key part of large service clusters aimed at satisfying all the needs and experiences expected by visitors. Food, shopping and entertainment services will also be fundamental components of the sun-and-beach cluster.

Beaches and their ancillary services will continue to be the major lure for visitors, although other attractions such as golf courses and theme parks will be a must in the traveler's agenda. To supplement these attractions, visitors will expect spectacular events as well as a broad supply of leisure and commercial activities.

Tourists' reactions and satisfaction with their experience will be constantly gathered and evaluated through the value chain, with visitor feedback sent to service providers in real time. One of the stakeholders most interested in this feedback will be the motivational centers.

This value chain will be backed up by several horizontal elements that will enhance the destination's operations. Firstly, the increasing complexity of mass sun-and-beach tourism will require effective, integrated management of the value chain implemented by professional firms. Secondly, highly integrated quality systems will be needed to guarantee service standards through the value chain. Thirdly, mass destinations will employ powerful technological platforms to provide visitors with continuously updated online information about attractions, accommodation and services. Finally, effective coordination between private agents and public bodies will be needed to ensure good planning and management of large, complex tourist destinations.

\subsection{Step 3: spatial visions}

After establishing the value chain operations, spatial planning requirements for destinations are defined. These requirements, extracted from recent foresight studies (OPTI \& Junta de Andalucía, 2008,2009 ), are a physical expression of tourist expectations for enjoying the experience and business requirements for efficient operation. Stakeholders' opinions were expressed as follows.

a) Direct transport connection with tourists' home markets. Mass tourism will require fast transport connections between home countries and final destinations. Direct connections with distant markets will be provided by regional airports. Connections with domestic markets will be preferably via by high-speed railways.

b) Intermodal connection between airport, railway and road systems. Handling large volumes of international and domestic tourists will require efficient connections between different transportation modes. For instance, an airborne visitor should be able to make a connection with local railway and road networks in a reasonable time.

c) Public transport connection between terminals and final destination. Airport and railway terminals should be connected to final destinations by comfortable and efficient 


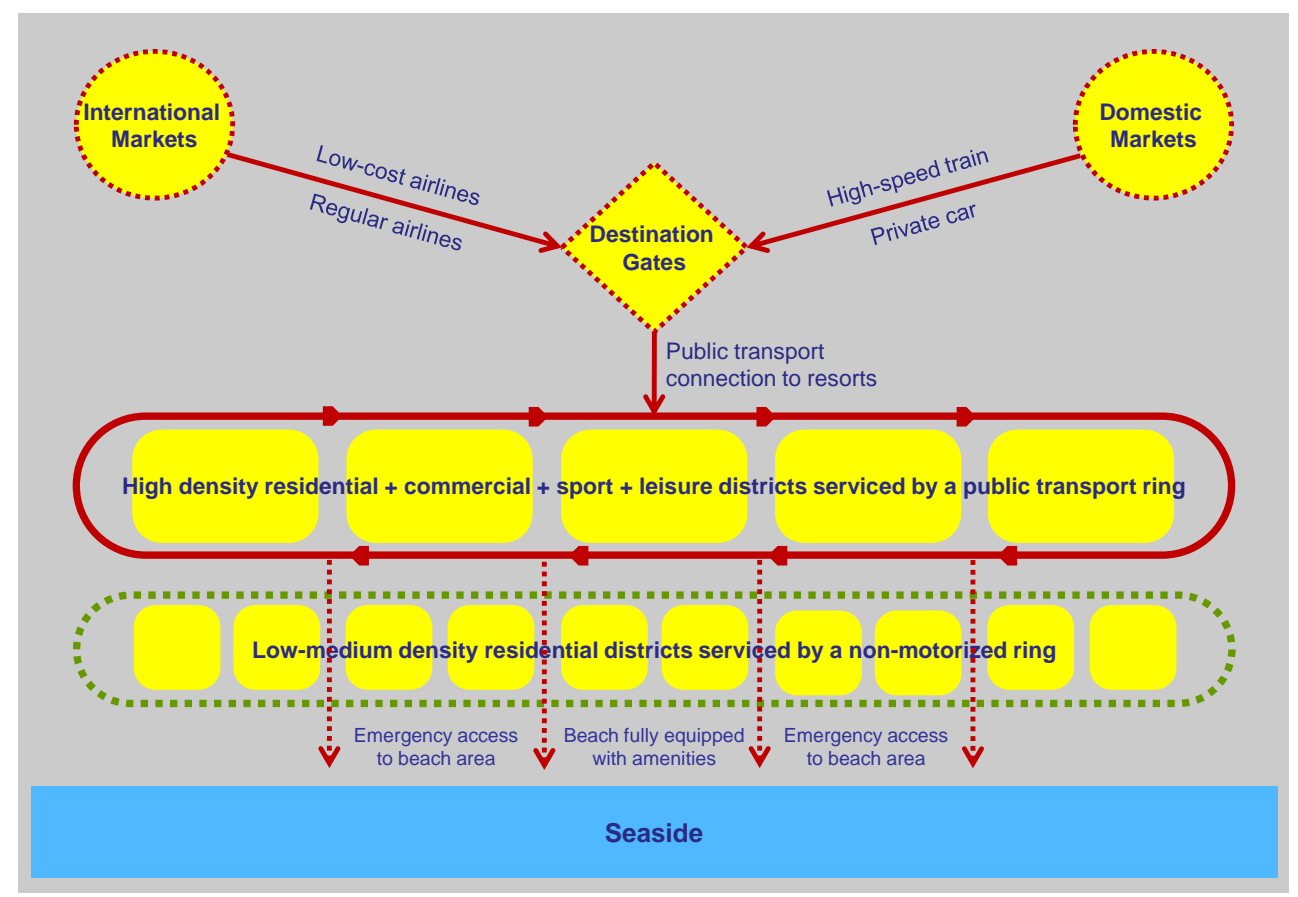

Fig. 4. Spatial planning model for sun-and-beach destinations (2025). Source: Author.

public transport systems. Electric buses and trams will provide an enjoyable and pollution-free ride between arrival terminals and residential complexes.

d) Intense, sustainable mobility at destinations. In order to avoid traffic congestion at destinations, the use of private vehicles will be discouraged, while the use of trams, electric minibuses, and non-motorized vehicles will be promoted. Ample pedestrian zones will be developed around commercial areas and along the seafront.

e) Provision of sustainable basic infrastructure. Large volumes of visitors will require the large-scale supply of basic infrastructure (water, energy, waste, telecom, etc.) without threatening the destination's sustainability. In order to optimize operational costs, infrastructure will be designed to supply average rather than peak demand.

f) Development of new residential models. Real estate products based on an apartment + hotel + golf mix will evolve toward more sophisticated models in which residential and recreational uses will comply with strict sustainability criteria.

g) Avoidance of urban sprawl. Ecological footprint and environmental impacts will be minimized. Fiscal incentives will favor residential time-sharing formulas in order to smooth destination seasonality and stop urban sprawl.

h) Spatial clustering of commercial and leisure activities. Large sun-and-beach destinations will require a wide range of shopping, restaurant and leisure activities, which will be clustered spatially to take advantage of agglomeration economies.

i) Ample supply of sport and cultural facilities. Sun-and-beach will probably continue to be the major motivational theme for tourist trips. However, beach destinations will have to offer numerous sport and cultural activities to attract the visitor of the future.

j) Interconnection of open spaces with the beachfront. Most tourists will reject high density and heavily congested destinations. The family and seniors segments will appreciate the existence of ample green spaces interconnected with the beachfront. k) Preservation of natural and urban landscapes. Future travelers will not accept polluted beaches, deteriorated landscapes or run-down destinations under any circumstances. Welldesigned public spaces, such as sea promenades, will be key elements to integrate commercial and residential complexes in the local landscape.

1) Integrated coastline planning. The complexity of services and infrastructures required by mass destinations will give rise to energetic public intervention to minimize environmental and social impacts. Integrated planning for the entire coastline will be necessary in order to ensure the right location of large tourist destinations.

As other authors have set out (Dredge, 1999; Gunn \& Var, 2002; Inskeep, 1988), spatial requirements can be translated into graphic models which broadly display the major territorial features of a tourist destination (see Fig. 4): tourist generating markets, gateways, access routes, nodes, circulation paths, districts, etc. These graphic models are of great help for involving stakeholders in discussions regarding broad spatial arrangements.

\subsection{Step 4: urban design visions}

In the fourth methodological step, functional and spatial requirements are incorporated into urban design patterns for key components of destinations such as large-scale infrastructure and facilities. Brief insights are given of the foreseeable evolution (present time to 2025 horizon) of an airport terminal and a hotel complex by the sea side. Each of the following patterns represents a design model taken to an extreme, and should be considered as mere working hypotheses. Though these two patterns do not exhaust the whole scope of a sun and beach destination, they provide significant clues about future urban design requirements.

\subsubsection{Designing the medium-size airport terminal of the future}

Recent studies (Amadeus, 2012) foresee rapid, significant changes in the design of airport passenger terminals over the next 20 years. The diverse range of factors influencing such changes will 
include technology innovations, consumption patterns and cultural desires. Since traveling will be an important part of the tourist experience, passengers will demand streamlined, stress-free holistic services at airport facilities. Travelers will expect more leisure options and more enticing retail options when waiting to board their plane. Breakthrough IT innovations will propel a revolution in the management and control of passenger flow at airport terminals. Growing public environmental awareness will put pressure on the airport system to reduce its ecological footprint.

A stereotype of a present airport terminal at a tourist destination could be described in the following terms (see Fig. 5): Terminals are mostly accessed by private cars and taxis, while the public transport system plays a secondary role if available at all. Parking lots for rental cars and private automobiles occupy large tracts of land. Old air terminals are not designed to comply with basic sustainability criteria. Large anonymous buildings contain check-in and boarding facilities as well as shopping and entertainment areas, with almost no space for relaxation. Terminals are made up of rigid structures unable to adapt to peak and low-season demand. Security controls are cumbersome, intrusive and time consuming. Passenger stress soars from check-in to the boarding areas. In brief, most contemporary air terminals seem to be more centered on airline needs than passenger well-being.

Compared to the old airport model, the terminal of the future will be designed as a complex environment with the passenger at its heart (see Fig. 5). Mass users will appreciate arriving at and leaving from a tourist destination through friendly, functional transport terminals. The airport will be efficiently connected to the tourist destination by innovative, reliable and greener public transport systems, multimodal connection with the railway system will be provided and the use of private automobiles will be discouraged. Terminal buildings will be more compact and more energy efficient to reduce their environmental footprint. Airport terminals will be made up of flexible modules so as to adapt their capacity to passenger volumes in peak and low seasons. Thanks to technological innovations, check-in areas will be substantially reduced and passengers will pass through security controls without stopping or disrobing. Designers will create a calm, functional and aesthetically pleasing airport environment based on bioclimatic principles. The provision of leisure and entertainment services will grow to attend the diversity of travelers' interests. Immersive and interactive technology will facilitate the personalization and tailoring of the local experience to specific interests such as cultural heritage or shopping. Air terminals will become an integral part of tourist destinations and create a "sense of place" through a sensitive combination of local architectural design, materials and colors. In other words, airports will evolve into more operationally efficient, secure, engaging and environmentally responsible facilities.

\subsubsection{Designing the hotel of the future}

The "Hotel for Tomorrow" concept has recently attracted the attention of researchers and industry alike (Amadeus, 2010; Björkqvist, 2009), who have identified several megatrends that may influence the hotel of the future. In the next 15 years, tourist demand will increase but markets will be more fragmented and segmented by lifestyles. Consumers will become more demanding, expecting not just rooms but experiences tailored to their needs and life styles. Growing awareness about environmental issues and sustainability principles will determine hotel designs and operations. Technological innovations will streamline management operations, automate basic processes and provide service customization. Hotel concepts will have shorter life spans, so they

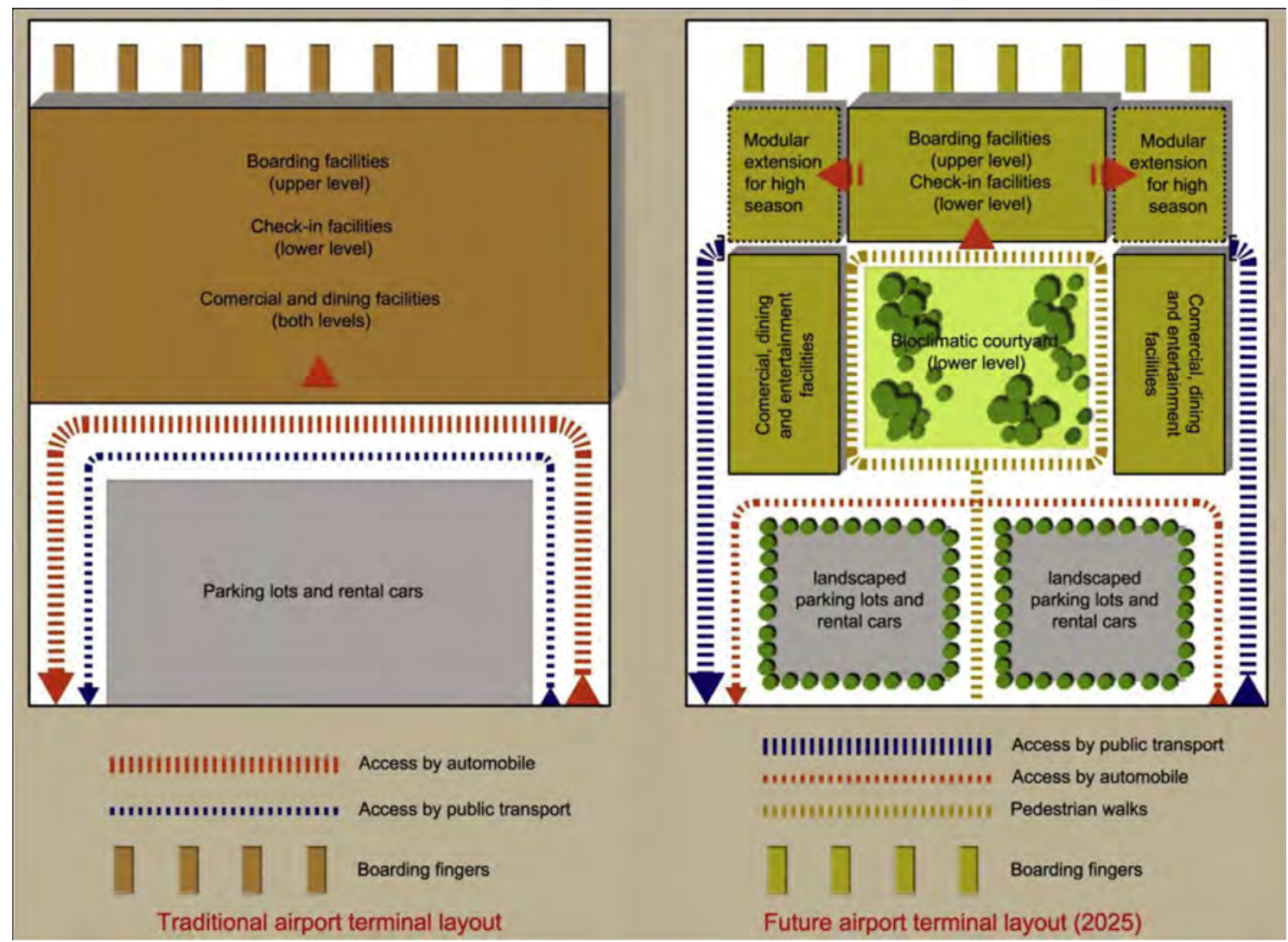

Fig. 5. Evolution of a medium-size airport terminal at a tourist destination. Source: Author. 
will have to be revamped every few years. Hotels will move from volume-based thinking towards value-based thinking.

Traditional sun-and-beach hotels in urban surroundings follow schematic patterns (see Fig. 6). Most hotel complexes are accessed by private automobiles or taxis because of the lack of an efficient and reliable public transport system. Excessive dependence on private cars generates traffic congestion and requires large expanses of land for parking lots. Physical connection with the seaside is often cut by a busy access road and a poorly designed sea promenade. Economic criteria drive the construction of large hotel buildings with rigid structures and predetermined spatial layouts. Common facilities are oversized because they are designed to attend seasonal peaks. Hotel complexes are large consumers of non-renewable energy resources and large producers of ecological footprints.

The hotel of the future will have some distinguishing features from past models (see Fig. 6). Hotel complexes will be served by an efficient, reliable, green public transport system which will allow parking lots to be reduced. The hotel compound will have a direct pedestrian link to the beach. Hotels will become smaller and more flexible due to fragmented customer needs. Hotel construction will shift to convertible and mountable buildings that meet the changing needs of time and customers. Rooms will be arranged in different modules with elements and functions tailored to guests' preferences and lifestyles. New technologies will allow for more automated services and less back-office space. Hotels will include sustainability criteria in their solutions at an early stage of the planning and construction process. Energy-saving technology will be standard choices, all hotel materials will be recyclable, and hotels will move from energy consumption to production. Micro power plants, energy recovery systems, gray water utilization and paperless functions will become attractive hotel features.

\subsection{Step 5: integrated spatial vision}

The urban patterns of major infrastructures and tourist facilities will provide a valuable input for shaping an integrated spatial vision of how a future destination will look like. Basically, there are two ways to undertake this final methodological step. One option is to display the future vision in a hypothetical ex-novo resort where no man-made structures condition the final design, and the other option is to do so with a mature and already operating tourist destination. Given the current prevailing sustainability concerns, a hybrid option is preferred in this exercise by developing a new resort adjacent to an old urban center.

The spatial planning outline (see Fig. 4) and residential design patterns (see Fig. 6) are synthesized in a fictitious sun-and-beach destination located somewhere on the Mediterranean coast (see Fig. 7). In the urban design criteria followed by this outline, special care is taken to guarantee a swift transport connection between the old urban center and the new tourist resorts. Secondly, great emphasis is given to the beachfront development with an exclusive pedestrian area that connects all the residential complexes as well as the common open space in the center. Thirdly, residential density is graded by proximity (high density) or distance (low density) from the public transport ring. Finally, a large open space is created as a backbone linking the beachfront with the sport facilities at the rear and with the pedestrian paths that facilitate access from the tourist residential complexes. In summary, in this destination model the public transport ring and the public spaces network act as the articulating drivers of the whole compound.

Step 5 finalizes Part II of the proposed methodological approach. Reaching this point, tourism planners are provided with conceptual schemes of what a generic sun and beach destination will look like on a future horizon. The resulting conceptual model can be

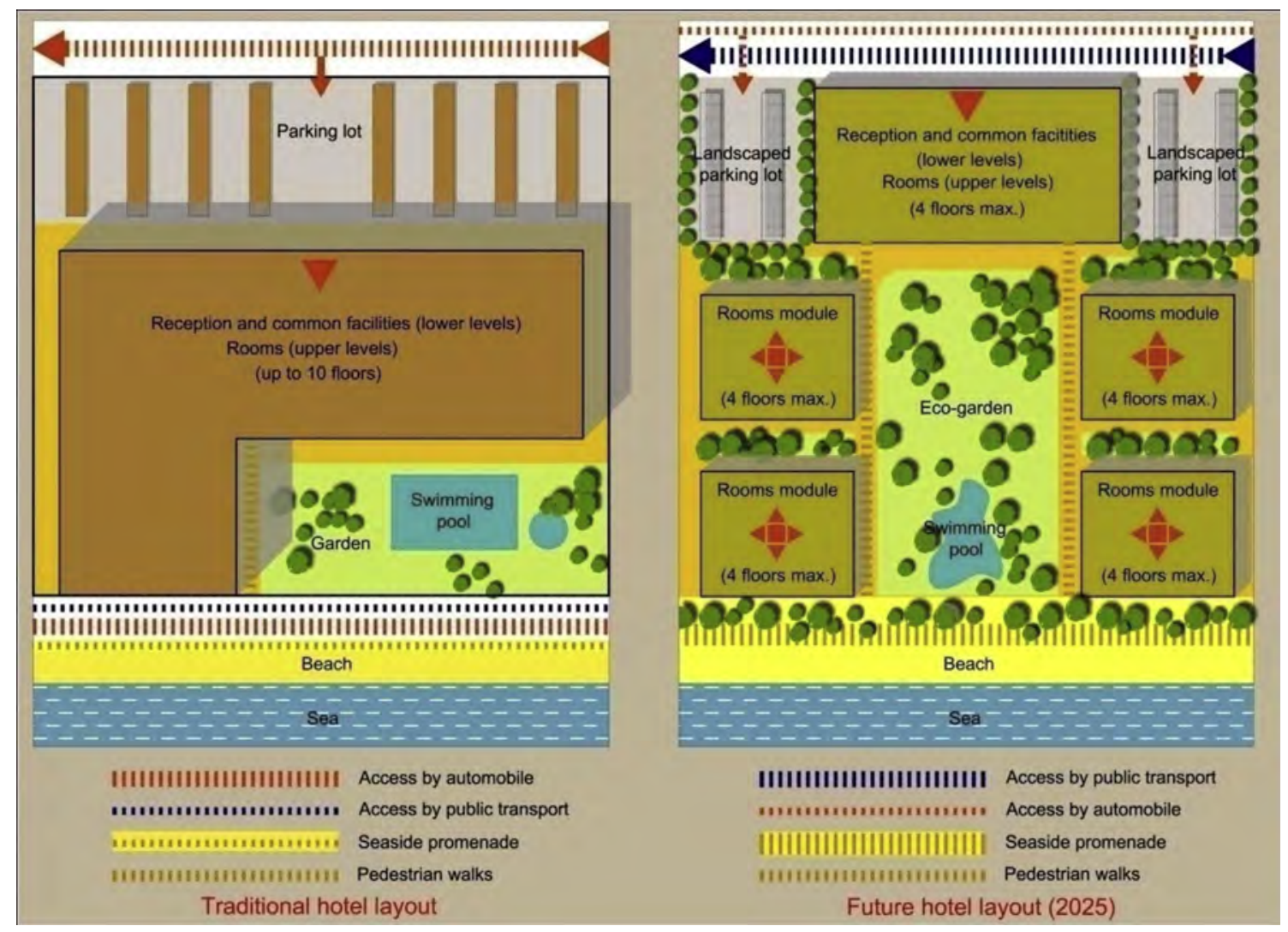

Fig. 6. Evolution of hotel layout at a sun and beach destination. Source: Author. 


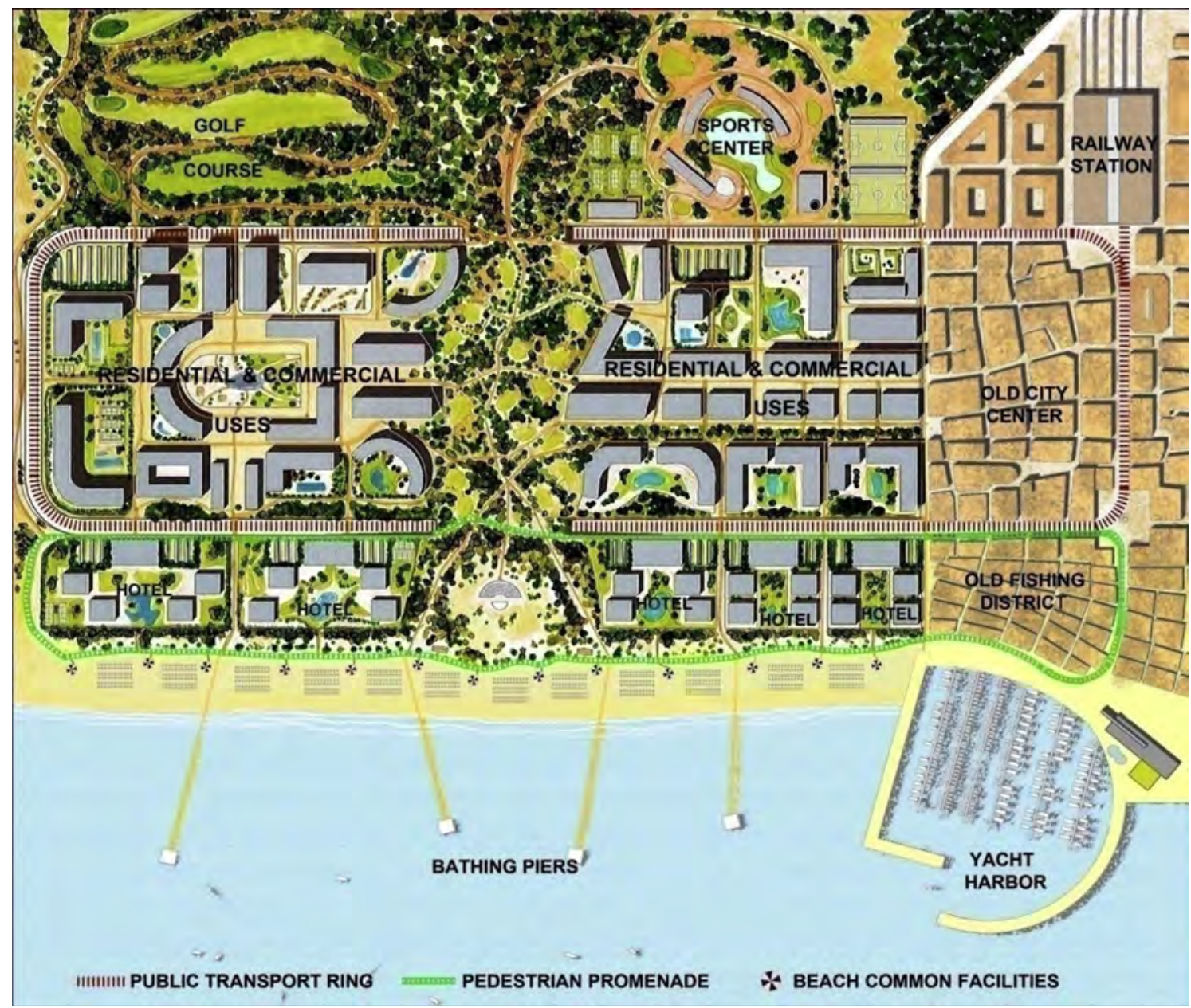

Fig. 7. Integrated vision of destination. Source: Author.

implemented either at ex-novo destinations or mature destinations that may fulfill future expectations of sun and beach mass demand (see Part III in Fig. 1). In both cases strategies will be formulated to breach the gap between model requirements and destination's existing conditions. Subsequent implementation steps will follow standard urban planning procedures established by local regulations.

\section{Conclusion}

This paper has raised the issue that there is a weak link between tourism spatial planning and foresight exercises, and, consequently, there is an opportunity for integrating more closely both processes. The absence of theoretical approaches reinforces the need for developing such a conceptual framework. Specific contributions of this paper can be drawn from the findings and experiences gathered during the research process.

Firstly, the proposed model may be particularly useful for incorporating foresight tools into national or regional planning strategies oriented either to develop new destinations or to renovate mature destinations. In this way, the cost of carrying out foresight studies would be spread among several destinations and at the same time it would provide regional planners with a common ground for formulating development strategies.

Secondly, the proposed foresight method appears to be userfriendly for decision makers and quite manageable for technicians. Although the approach is process-oriented, it generates a tangible product - future visions, general strategies and physical design guidelines - which people can easily refer to and understand. Similar foresight experiences in the tourism realm support the friendliness and effectiveness of the proposed method (Amorim et al., 2011; Duim \& Calders, 2004).

Thirdly, this foresight approach may be welcomed by both strategic and physical planners. It offers a comprehensive future vision of tourism demand and its business implications, and also illustrates spatial solutions. Analytical tools as the ones used in the proposed model are frequently applied when undertaking strategic and marketing plans for destinations (Buhalis, 2000; Hall, 2008) and they are also well-known by corporate managers in the tourism industry (Athiyaman \& Robertson, 1995).

Fourthly, the method's outcomes provide an opportunity to breach the gap between tourism stakeholders' goals for profitmaking and spatial planners' sustainability concerns. In this respect, efforts for finding a common ground for discussions have been done previously by several authors (Jamal \& Getz, 1995; Sautter \& Leisen, 1999).

Finally, this approach illustrates the potential of foresight tools for knowledge dissemination and for the establishment of expert networks (Quist, 2009), which together can help to improve a destination's governance. Moreover, foresight exercises involving stakeholders can result in the development of future visions that provide guidance and orientation to the tourism planning process (Duim \& Calders, 2004; Fernández Güell \& Redondo, 2012). 
However, in its present state of development, the proposed model has several limitations. First and foremost, it is just a generic and conceptual framework that needs to be applied to real sun and beach destinations, preferably mature, in order to test rigorously its feasibility. This test will enable researchers to check the plausibility of the approach and will provide planners with a road map for adapting mature destinations to future demand requirements.

Second, a whole set of urban patterns have to be developed to get a complete overview of a destination's basic elements. Just as well, planning criteria should be established which correspond to the future vision of a "competitive and sustainable destination". This line of research should follow the work initiated by prior researchers in the field of destination design (Dredge, 1999; Gunn \& Var, 2002).

Third, attention should be paid on how visions are influenced by the exits and entries of stakeholders along the foresight exercise, and how emerging visions face competition from the regular dominant vision supported by vested interests and actors (Quist, 2009). Just as well, more exploratory work should be done with stakeholders' involvement in the design phase to guarantee that they can add value when discussing urban design patterns. Further work needs to be done in identifying appropriate methods of enquiry to better understand network interrelations among stakeholders (Dredge, 2006).

Forth, the method, as it is right now, does not contemplate the possibility of plugging in quantitative models that would certainly enrich the whole approach. As it have been suggested by some authors (Davies, 2003; Song \& Li, 2008), a concurrent use of quantitative and qualitative tools would improve the accuracy of tourism forecasts. Thus, quantitative tools could be employed to support and lend coherence to the proposed process, but they should never drive it because the method would lose its eminently qualitative nature.

The above mentioned limitations expose clear opportunities for further lines of enquiry that bring together academicians and professionals working in the practice of tourism planning. Execution of further research will enhance the potential of this approach for incorporating foresight as an undisputed work package in the tourism planning processes.

In summary, this paper shows the potential of foresight for dealing with tourism development issues burdened by complexity and uncertainty, as well as its capability to bring down analysis from global challenges to local and spatial implications. Obviously, the proposed approach requires further development and refinement, but when this is achieved, chances are that foresight will arouse less technical skepticism amongst tourism planners.

\section{Submission declaration}

A preliminary and shortened version of this paper was presented in the 6th Conference of the International Forum on Urbanism, Barcelona, 25-27 January, 2012, under the title "Foresight as an innovative tool for designing tourist destinations". That preliminary paper was also published as part of the Conference's Proceedings in ARA Journal of Tourism Research, Vol. 3, $\mathrm{N}^{\circ}$ 2, 2011. The present paper submitted to Tourism Management is a much more advanced methodological version than the previous article published in ARA.

\section{Acknowledgments}

The authors wish to acknowledge the contribution of doctoral students Carlos Olmos and Rosa Amorós to this research study.

\section{References}

Abott, J. (2005). Understanding and managing the unknown: the nature of uncertainty in planning. Journal of Planning Education and Research, 24, 237-251.

Amadeus. (2010). Hotels 2020: Beyond segmentation [pdf document]. URL http:// www.amadeus.com Accessed 26.09.12.

Amadeus. (2012). Reinventing the airport ecosystem [pdf document]. URL http:/ www.amadeus.com Accessed 26.09.12.

Amelung, B., \& Moreno, A. (2009). Impacts of climate change in tourism in Europe. PESETA tourism study. Sevilla, Spain: Institute for Prospective Technological Studies.

Amorim, C. Melo, C., Alvarenga, A., \& Soeiro, P. (2011). Scenarios and possible futures for hospitality and tourism. Foresight, 13(1), 19-35.

Armstrong, J. S. (2001). Principles of forecasting. New York: Springer.

Athiyaman, A., \& Robertson, R. W. (1995). Strategic planning in large tourism firms: an empirical analysis. Tourism Management, 16(3), 199-205.

Björkqvist, A. (2009). Concepting the hotel for tomorrow. Helsinki, Finland: HAAGAHELIA University of Applied Sciences.

Buhalis, D. (2000). Marketing the competitive destination of the future. Tourism Management, 21(1), 97-116.

Butler, R. (2009). Tourism in the future: cycles, waves or wheels? Futures, 41, $346-$ 352.

Chambers, E. (2009). From authenticity to significance: tourism on the frontier of culture and place. Futures, 41, 353-359.

Chettiparamb, A., \& Thomas, H. (2012). Tourism and spatial planning. Journal of Policy Research in Tourism, Leisure and Events, 4(3), 215-220.

Cole, S. (2001). Dare to dream: bringing futures into planning. American Planning Association Journal, 67(4), 372-383.

Cole, S., \& Razak, V. (2009). Tourism as future. Futures, 41, 335-345.

Consejo Español de Turismo. (2007). Plan del turismo español horizonte 2020 Madrid: Secretaría General de Turismo, Ministerio de Industria, Turismo y Comercio.

Darbellay, F. \& Stock, M. (2012). Tourism as complex interdisciplinary research object. Annals of Tourism Research, 39(1), 441-458.

Davies, B. (2003). The role of quantitative and qualitative research in industrial studies of tourism. International Journal of Tourism Research, 5, 97-111.

Dredge, D. (1999). Destination place planning and design. Annals of Tourism Research, 26(4), 772-791.

Dredge, D. (2006). Networks, conflict and collaborative communities. Journal of Sustainable Tourism, 14(6), 562-582.

Dredge, D., \& Moore, S. (1992). A methodology for the integration of tourism planning in town planning. The Journal of Tourism Studies, 3(1), 8-21.

Duim, V. R. van der, \& Calders, J. (2004). The margins of Texel. Journal of Sustainable Tourism, 12(5), 367-387.

Dwyer, L., Edwards, D., Mistilis, N., Roman, C., \& Scott, N. (2009). Destination and enterprise management for a tourism future. Tourism Management, 30, 63-74.

Engel, J. F., Blackwell, R. D., \& Miniard, P. W. (1990). Consumer behavior. Chicago: Dryden Press.

European Commission. (2009). Mapping foresight: Revealing how Europe and other world regions navigate into the future. Brussels: European Commission.

European Commission - JRC - IPTS. (2005). FOR-LEARN guide. URL http://www. forlearn.jrc.ec.europa.eu Accessed 06.03.13.

European Foresight Platform (EFP). (2012). EFP briefs [pdf documents]. URL http:// www.foresight-platform.eu Accessed 26.09.12.

Fernández Güell, J. M. (2006). Planificación estratégica de ciudades: Nuevos instrumentos y procesos. Barcelona, Spain: Reverté.

Fernández Güell, J. M. (2011). Recuperación de los estudios del futuro a través de la prospectiva territorial. Ciudad y Territorio - Estudios Territoriales, 167, 11-32.

Fernández Güell, J. M., \& Redondo, L. (2012). Linking territorial foresight and urban planning. Foresight, 14(4), 316-335.

Foresight for Regional Development Network (FOREN). (2001). Practical guide to regional foresight. Sevilla, Spain: Institute for Prospective Technological Studies.

Gavigan, J. P., \& Scapolo, F. (2001). La prospectiva y la visión del desarrollo regional a largo plazo. The IPTS Report, 56, 22-33.

Georghiou, L., Cassingena, H., Keenan, M., Miles, I., \& Popper, R. (Eds.). (2008). The handbook of technology foresight: Concepts and practice. Cheltenham, England: Edward Elgar.

Getz, D. (1986). Models in tourism planning: towards integration of theory and practice. Tourism Management, 7(1), 21-32.

Goodwin, P. (2008). A quick tour of tourism forecasting. Foresight, 10, 35-37.

Gunn, C. A., \& Var, T. (2002). Tourism planning: Basics, concepts, cases. New York: Routledge.

Hall, C. M. (2008). Tourism planning: Policies, processes and relationships. Harlow, England: Prentice Hall.

High Level Group on Tourism and Employment. (1998). European tourism - New partnerships for jobs (Unpublished report).

Inayatullah, S. (2004). Casual layered analysis: theory, historical context, and case studies. In S. Inayatullah (Ed.), The casual layered analysis (CLA) reader (pp. 849). Taipei, Taiwan: Tamkang University Press.

Inskeep, E. (1988). Tourism planning: an emerging specialization. Journal of the American Planning Association, 54(3), 360-372.

IPK International. (2012). ITB world travel trends report. Berlin, Germany: Messe Berlin Gmbh.

Jamal, T. B., \& Getz, D. (1995). Collaboration theory and community tourism planning. Annals of Tourism Research, 22(1), 186-204. 
Jantsch, E. (1967). Technological forecasting in perspective. Paris: OECD.

Kaynak, E., \& Macaulay, J. A. (1984 June). The Delphi technique in the measurement of tourism market potential. Tourism Management, 87-101.

Lund-Durlacher, D., \& Dimanche, F. (2013). Mobilities and sustainable tourism: an introduction. Journal of Sustainable Tourism, 21(4), 505-510.

Mittringer, R. (2005). Austrian tourism 2015. Foresight brief $N^{\circ} 52$, the European fore sight platform (EFP). URL http://www.foresightplatform.eu Accessed 26.09.12.

Myers, D., \& Kitsuse, A. (2000). Constructing the future in planning: a survey of theories and tolos. Journal of Planning Education and Research, 19, 221-231.

Observatorio de Prospectiva Tecnológica Industrial (OPTI). (2005). Estudio de prospectiva del sector turismo: Escenarios de demanda global y tendencias tecnológicas. Madrid, Spain: OPTI.

Observatorio de Prospectiva Tecnológica Industrial (OPTI) \& Junta de Andalucía. (2008). Demanda turística en Andalucía y sus implicaciones en el sector turismo. Sevilla, Spain: Junta de Andalucía.

Observatorio de Prospectiva Tecnológica Industrial (OPTI) \& Junta de Andalucía. (2009). Exigencias futuras de los mercados de origen del turismo en Andalucí (Unpublished report).

Organization for Economic Co-operation and Development (OECD). (2010). OECD tourism trends and policies 2010. Paris: OECD.

Porter, M. (1980). Competitive strategy: Techniques for analyzing industries and competitors. New York: Free Press.

Quist, J. (2009). Stakeholder and user involvement in backcasting and how this in fluences follow-up and spin-off. Joint actions on climate change conference, Aalborg, Denmark, 8-10 June 2009.

Richins, H. (1997). Community tourism development scenarios and their use in tourism research. Asia Pacific Journal of Tourism Research, 2(1), 31-42.

Romero, I., \& Tejada, P. (2011). A multi-level approach to the study of production chains in the tourism sector. Tourism Management, 32, 297-306.

Sautter, E., \& Leisen, B. (1999). Managing stakeholders: a tourism planning model. Annals of Tourism Research, 26(2), 312-328.

Slaughter, R. A. (1999). A new framework for environmental scanning. Foresight 1(5), 387-397.

Song, H., \& Li, G. (2008). Tourism demand modeling and forecasting: a review of recent research. Tourism Management, 29, 203-220.

Tourism Sustainability Group. (2007). Action for more sustainable European tourism (Unpublished report).

United Nations Industrial Development Organization (UNIDO). (2005). UNIDO technology foresight manual. Vienna: UNIDO.

Van Doorn, J. W. M. (1986). Scenario writing: a method for long-term tourism forecasting? Tourism Management, 7(1), 33-49.

Wachs, M. (2001). Forecasting versus envisioning: a new window on the future Journal of the American Planning Association, 67(4), 367-372.

World Tourism Organization (WTO). (2001). 2025 vision. In Global forecast and profiles of market segments (Vol. 7). Madrid, Spain: WTO.
World Tourism Organization (WTO). (2006). Tourism 2020 vision. Madrid, Spain: WTO.

World Tourism Organization (WTO). (2011). Tourism towards 2030: Global overview. Madrid, Spain: UNWTO.

Yeoman, I., \& Lederer, P. (2005). Scottish tourism: scenarios and vision. Journal of Vacation Marketing, 11(1), 71-87.

Yeoman, I., Rebecca, T. L. Y., Mars, M., \& Wouters, M. (2012). 2050 - Tomorrow's tourism. Bristol: Channel View Publications.

Zhang, X., Song, H., \& Huang, G. Q. (2009). Tourism supply chain management: a new research agenda. Tourism Management, 30, 345-358.

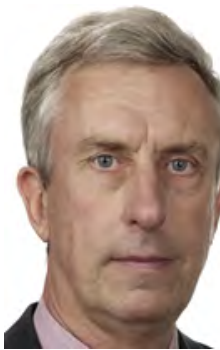

José M. Fernández-Güell. He has a Bachelor degree in Architecture from Universidad Politécnica de Madrid as well as a Master and a PhD in Urban and Regional Planning from Texas A\&M University. Presently, he is Deputy Director of Research of the School of Architecture, Professor of the Urban and Regional Planning Department and member of the GIAU $+S$ research group at the Universidad Politécnica de Madrid. He has been a consultant for the European Commission, the Inter-American Development Bank and the United Nations Industrial Development Organization. He is the author of several articles and books related to strategic planning and foresight tools.

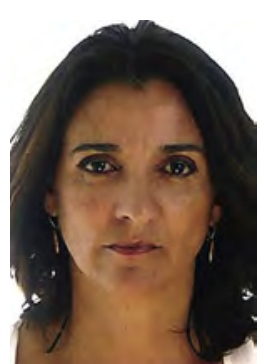

Marta Collado. She has a Bachelor degree in Architecture from Universidad Politécnica de Madrid. Presently, she is a doctoral student at the Urban and Regional Planning Department of Universidad Politécnica de Madrid. She has worked as an urban planner in a consulting firm for 10 years. 